\title{
Patterns of Preference and Practice: Bridging Actors in Wildfire Response Networks in the
}

\section{American Northwest \\ Networks in Disasters}

The roles of bridging actors in emergency response networks can be important elements in the outcomes of disaster response (Kapucu 2006; Nowell and Steelman 2014). Bridging actors connect portions of the network that might otherwise be disconnected, enabling information and resources to flow from one part of the network to another. This flow of information has been identified as critical to effective incident response (Steelman et al. 2011), but there is currently a dearth of empirical literature on the efficacy of these bridging actors. Building the theoretical and practical knowledge that informs these relationships is important to longer term efficacy in disaster response.

This paper is based on a study of wildfire preparedness and response networks in twentyone large wildfires from 2012 to 2013 in counties in the wildland-urban interface (WUI) near national forests in Idaho, Montana, Oregon, and Washington. In wildfire response, we would expect different segments of a response network (e.g., law enforcement, land management, fire service, animal services, citizen groups, and local, state, and federal government) to coordinate more effectively if multiple bridging actors tied these segments together. In this study, we investigated how key individuals in responder networks anticipated seeking out specific people in perceived bridging roles prior to the occurrence of wildfires, and then we captured who actually assumed these roles during large-scale wildfire events. This study enabled us to explore the extent to which people's preferences for bridging actors approximated who actually played these roles in 21 different incident response networks. By understanding who people anticipated seeking and then identifying who actually played these roles, we can plan more realistically for 
effective disaster response and contribute to understanding critical relational dynamics that remain central in disaster scholarship across multiple disciplines (McEntire 2007).

Entanglements and Emergent Networks in Incident Response

In the American West, wildfire has been recognized as a hazard since the earliest European settlements (Carroll et al. 2006; Pyne 2001). Wildfires are in many ways exemplary of the types of human-environment relationships that have led many social scientists to question the extent to which environmental disasters can be considered "natural." While the American wilderness and the conditions affecting fire susceptibility are products of centuries of human activity that intensified with the westward expansion of European settlements (Lightfoot et al. 2013; Anderson 2006), fires burning on wildlands are often vital to ecological processes that sustain these natural systems. The potential for disaster arises when fires spread to the intersection of wildland and human settlements, commonly referred to as the WUI. Importantly, it is not only wildfires that spread to human settlements; recent decades have seen significant growth — an increase of 52 percent between 1970 and 2007 (Theobald and Romme 2007)—of human settlements into fire-prone wildland (see also Schoennagel et al. 2009). Moreover, the risk of wildfire disasters has increased with anthropogenic climate change, which has contributed to increases in wildfire size and intensity (Running 2006; Brown et al. 2004).

The management of federal lands has long involved competing interests, with the tensions between various local groups, indigenous peoples, and federal land agencies characterized as "collisions of worlds" (Anderson 2006)_especially in the American West. These issues have been reviewed extensively (Cuthane 1981; Fedkiw 1998; Krannich and Smith 1998), with scholars noting that stakeholder groups have competing agendas vis-à-vis the management, consumption, and conservation of federal land resources (Fleming et al. 2015). All 
of these stakeholders are variously dependent upon a common set of natural resources, linking them together through this mutual dependence. Though various stakeholders occasionally form cross-cutting alliances around land and fire management issues (Walker 2003; McCarthy 2002), the tensions and historical relations between these groups and organizations are particularly salient during large scale wildfire response, often as a result of issues of jurisdiction, trust, and insider/outsider frictions (Carroll et al. 2004; Carroll et al. 2006). Thus, the production of wildfire risk by human activity — combined with the historical tensions and entanglements around natural resource management, and the legitimacy of different agencies and stakeholder groups in the American West - has the cumulative effect of introducing relational dynamics as a core element of incident complexity, which makes the question of network bridging particularly salient in wildfire response.

The responder network has been defined as "the collection of individuals, organizations, and agencies that have sustained involvement during the event who aim to serve the community in minimizing and coping with damages brought on by the disaster" (Nowell and Steelman 2012, p. 235). In a responder network in large wildfires, relational dynamics are critical elements that can be characterized by relationship complexity along with the competing interests of key stakeholders, thus making the need for bridging ties relatively important. Interaction and communication patterns in response networks are more emergent than programmed (Choi and Brower 2006) and yet these patterns of interactions are not independent from previous institutional arrangements (Nowell and Steelman 2014). Importantly, breakdowns in communication in one area of response networks have the potential to result in cascading failures in other areas (Nowell and Steelman 2014). 
Because communication issues can result in problematic and potentially dangerous outcomes, there is an urgent need for research that can go beyond identifying barriers to effective network performance and begin to identify roles and actions that can overcome these barriers. Response networks in large wildfires are composed of local actors-emergency management, fire, law enforcement, sheltering agencies — and non-local actors — federal or state wildfire responders who may or may not be familiar with the region in which they work (Nowell and Steelman 2014). The crisis-borne necessity of having local and non-local actors work together can create considerable tension, if not conflict. In their case studies of wildfire response in the American West, Carroll and colleagues (2006) found that a lack of mechanisms for bringing together the different orientations present in the response network resulted in disruptions in local interactions and increased conflict. Incident management teams (IMTs)—who provide a paramilitary management infrastructure for the logistical coordination of state, local, and federal emergency responders and government and non-governmental agencies are granted unusual levels of authority and are not necessarily beholden to locally-existing relationships and power structures (Carroll et al. 2006). Moreover, people in disaster-affected communities "often think the rules and regulations of public safety and helping organizations are another intrusion into their already disrupted lives" (Carroll et al. 2006:262, citing Schneider 1992). The Incident Command System - the organizational strategy for emergency response operations in the US National Incident Management System - is sometimes experienced by local communities as a gap-creating process that inhibits community action in emergencies (Carroll et al. 2006). In this paper, we examine some of the factors that might affect the bridging of these network gaps. Bridges in Wildfire Response Networks: Trust, Homophily, and Embeddedness 
Bridging actors connect disconnected actors and groups in a given network. Bridging processes fundamentally entail working across boundaries - specialization, organizational, sectoral, scalar, and often geographic. Information sharing is associated with increased learning capacity in partnerships (Manring 2007) and cooperation can be more effective if there are ties that span multiple boundaries of geography, expertise, and ideology (Schneider et al. 2003). Actors who serve as bridges in networks - connecting different network subgroups - have proven critical in facilitating the flow of information and influence (Kapucu 2006; Burt 1992) and have access to more diverse resources beyond their organization, group, or jurisdiction than do other members of the network (Bodin et al. 2006).

Two broad theoretical frameworks support different expected outcomes relating to who people might prefer as bridgers and who might actually play these roles during a disaster (see Table 1 for summary). The literature related to trust and familiarity suggests that people would likely see those with whom they are familiar and whom they trust as ideal bridgers during these situations (McCaffrey et al. 2013; Powell et al. 2005). Perceptions of who could and should play bridging roles are situated and based on, among other things, historical relations (Bryson et al. 2006), trust (Lundin 2007; Perrone et al. 2003), homophily (Burt 1992), and relational embeddedness (Nowell and Steelman 2014). In emergency situations, people tend to trust and take action on messages that come from familiar sources, but those sources are not necessarily the most useful (Velez et al. in review; Steelman et al. 2014; Fitzpatrick and Mileti 1991).

Alternatively, the literature from policy (John and Christopher 2000), administration (Steelman et al. 2012), environmental studies (Heberlein 2012; Schultz 2011), and organizational studies (Milward and Provan 2000) points to several reasons why there might be a low correspondence between pre-incident preferences and the actual composition of networks during 
a wildfire incident. A recent study by Nowell and Steelman (2014) sheds preliminary light on this question in the context of communication networks, finding that relational embeddeness was a stronger predictor of communication networks during disasters relative to institutional embeddedness. However, there is no known research to date which investigates this question in the context of positions of brokerage. These unresolved tensions in the literature make a compelling case for empirical work to bring clarity not only to the theoretical literature, but provide insight into practical action as well.

\section{INSERT TABLE 1 ABOUT HERE [Table 1. Similarity and Dissimilarity Theses] The Similarity Thesis: Trust, Homophily, and Relational Embeddedness}

Trust is an important component in building relationships. In their review of 64 articles published between 2000 and 2008 on public acceptance of fire and fuels management, McCaffrey et al. (2013, p. 16) found that the two variables most commonly identified as increasing the acceptance of procedures were familiarity with techniques and trust in people implementing the procedures. Burt (1992) established a direct connection between trust and homophily - a sociological principal that holds that people who have similar characteristics are more likely to interact with each other than people who are dissimilar (McPherson et al. 1987). A sizable body of empirical research has identified homophily as a core relational variable underwriting the formation of groups and organizations (Petev 2013; McPherson et al. 2001), facilitating effective communication (Rogers 1995), and the growth of inter-organizational collaboration (Powell et al. 2005). There is also a wealth of empirical evidence that suggests that shared ties to organizations and collectives (Frank 2009) or ideologies (Anderson 1983) serve as powerful proxies for homophily in facilitating interaction, relationships, and communication. 
Nowell and Steelman (2014) studied networks and interaction on three large wildfires in the American Southwest. They were interested in the extent to which two different types of embeddedness — relational and institutional — helped predict frequency and quality of interaction among responders during large WUI wildfires. In their model, relational embeddedness referred to the extent to which individual responders had direct, personal relationships prior to the incident, and institutional embeddedness referred to the extent to which individuals had shared affiliations or roles. They found that both factors contributed to higher frequency of and/or improved interaction in emergent response networks, but relational embeddedness (familiarity) played a stronger role than did institutional embeddedness (similarity). In a finding consistent with the homophily principle, institutionally embedded actors were more likely to interact with one another during wildfire incidents, but this was not associated with less problematic communication (Nowell and Steelman 2014, p. 17-18). Specifically, they found that those with institutional embeddedness but no relational embeddedness were more likely to experience problematic communication; that is, perceived similarity when not tempered by personal familiarity was associated with more problematic communication.

\section{The Dissimilarity Thesis: Why We Might See Differences in Anticipated vs. Actual Bridgers}

Importantly, bridging actors not only connect those who are disconnected, but are also more likely than others to connect dissimilar actors and organizations (Granovetter 1982, p. 108; Coser 1975, p. 257). The multiple jurisdictional, functional, cultural, and social differences in disaster response networks in many ways require some degree of bridging to facilitate coordinated action across pre-existing divisions. Thus, a universal tendency toward homophily might conceivably be counterproductive, as bridging is counter to the emergent concretization of boundaries we might expect from high levels of homophilic preferences. There are, however, a 
number of reasons why we might expect differences in anticipated vs. actual bridgers in wildfire incidents.

First, we know that plans which outline what responders expect will happen during an incident often do not reflect the realities of what actually happens during incidents (Choi and Brower 2006; Kapucu 2006). This finding has opened up an important area of inquiry concerning the relationship between preferences and expectations in advance of an incident and the realities of what happens during an incident. To date, progress on this research agenda has been modest. For example, Choi and Brower (2006) found significant de-coupling between formalized plans for who should be the primary point of contact for a given emergency response function and responder expectations about who they would likely go to during an incident. However, to date, no study has looked at whether those who are most trusted to fill the role ahead of an incident reflects who actually does serve in this role during an incident.

Second, in complex networks, it is highly unlikely that any single actor or organization will meet all needs and expectations as a bridging actor (John and Christopher 2000). Different actors in a network might exhibit different or even conflicting preferences for who should occupy such roles; thus, members of Group 1 may prefer bridging Actor A when collaborating with Group 2, while Group 2 may prefer bridging Actor B. The complexity of this scenario increases markedly with increased network size, as with wildfire response networks comprised of emergency responders, law enforcement, officials from local, state, and federal agencies, federal land agencies (e.g., U.S. Bureau of Land Management and U.S. Forest Service), IMT personnel, and members of the media. In other words, as the network gains more members, and as there is more overlap in responsibility within the network, it becomes more likely that different groups prefer different bridging actors. Therefore identifying effective bridging actors 
is often complex, and pre-incident expectations do not always match up with the structure and features of an emergent, incident-based network.

Third, though trust may be a core variable in explaining the preference for some bridging actors over others, operational factors come into play as well. For example, John and Christopher (2000) claim that organizations tasked with directly managing programs are not likely to be effective intermediaries in network cooperation. In wildfires, fire service agencies have very specific and time-sensitive responsibilities to fight wildfire or protect structures and populations in the WUI and therefore might simply not have the time and wherewithal to play key leadership roles in facilitating coordination with incident management teams and the greater incident response network. In contrast, Milward and Provan (2000; Provan and Milward 2001) studied governing networks of public agencies, specifically comparing and contrasting four contracted nonprofit systems that offered mental health services in communities across the US. They found that organizations that produce at least some of the services in the system will be more effective at governing a set of providers than principals that only govern without having any operational role.

Finally, when anticipating what one would do in a disaster, attitudes may differ from behavior because individuals are (often quite suddenly) enmeshed in a completely different social network during the disaster than before the disaster. People may have attitudinal preferences for courses of action, but a wealth of mitigating factors may contribute to a behavioral divergence from those attitudes (Heberlein 2012; Schultz 2011). As it stands, there is a dearth of empirical research on the divergence of attitude and behavior in the context of disaster response networks. One exception is a study by Steelman et al. (2012) who surveyed 873 residents on five large wildfires in the American West in 2009 and 2010 to explore the types of 
information that people want, trust, and use during a wildfire. They found that the sources that were used prior to wildfires were positively correlated with sources used during the fire, but that there were significant gaps between sources used and sources that were perceived as most useful or trustworthy. This underscores our earlier point that it is reasonable to expect a lack of correspondence between preferred and actual bridging ties, and such incongruence could have important implications for response network performance.

\section{Methodology}

Data for this study were drawn from a larger longitudinal study of factors that influence incident response to wildfires in the American West (see firechasers.ncsu.edu). This study consisted of data collected at two time points. First, to study the correspondence between preferred and actual bridging ties in wildfire incidents, we first captured the actors and organizations identified by local government and incident response agencies as ideal bridging actors in large wildfires involving IMTs prior to the 2013 wildfire season. Second, we identified the types of actors and organizations identified by local government and incident response agencies as having performed the roles of bridging actors in twenty-one large wildfires in our study region. We then compared the pre-fire season findings with the during-fire season findings to identify and explain patterns of correspondence and differences in pre-fire ideals and actual incident roles. Finally, we explored patterns in the types of actors and organizations that were identified by different respondent groups.

\section{Data and Sample}

Pre-Fire Survey. In the fall/winter of 2012/2013, we conducted a survey of county/municipal disaster response agency leaders from 109 counties identified as at-risk for wildfire in Idaho, Montana, Oregon, and Washington. These local agencies included responders 
such as county office of emergency managers (OEM), county sheriffs, fire departments, animal rescue, and the American Red Cross, as well as local government offices, such as mayor's offices, county commissioners, and municipal and county administrators. A total of 1801 individuals were surveyed and surveys were received from 706, resulting in a response rate of 45 percent $(n=654)$ at the organization level, and 39 percent at the individual level, which is consistent with web-based survey response rates (cf. Baruch and Holtom 2008). Non-response analysis indicated this sample over-represented fire service (44\%) and municipal government $(20 \%)$ and under-represented county government (12\%), law enforcement (8\%), and animal services (4\%). Additionally, county offices of emergency management were underrepresented $(12 \%)$, but unlike other agency types, there was only one county emergency management office per county and the response rate for emergency management offices $(64 \%)$ was more than 20 percent higher than any other category.

Post-Fire Survey. A total of 21 significant fire events occurred in our pre-fire survey sample region during the summer of 2013. Organizations from all counties that participated in the pre-fire survey which experienced a significant fire event that threatened human populations ${ }^{1}$ during the summer of 2013 were invited to participate in a post-fire survey in early fall of 2013. Surveys were sent to all agency leaders who were actively involved in incident response. In the end, we identified a total of 329 organizations or units (e.g., USFS districts) and 805 individuals for all 21 incidents. Our final response rate was 60 percent at the organization level $(n=196)$ and 58 percent $(\mathrm{n}=478)$ at the individual level. For this study, we included only local responders from those 19 counties that were part of both the pre-fire and post-fire samples, which reduced our total number of agencies to 134 and total respondents to 159 for both samples combined. Nonresponse analysis indicated that county government, fire service, law enforcement, county

\footnotetext{
${ }^{1}$ Operationalized as a Type I or Type II fire event involving evacuations, road closures and/or structures threatened.
} 
emergency management, and state government constituted 67 percent of the post-fire survey sample, while all others combined represented less than 33 percent.

Measures

Trusted Community Bridgers - Pre-fire. To identify potential bridging actors in pre-fire responder networks, we were first interested in which actors and organizations different members of a potential response network were likely to trust. As part of the pre-fire survey, leaders were asked the following:

During a large scale wildfire event, Type I or Type II Incident Management Teams (IMT) are often brought in from outside the area to manage the incident and may have limited local knowledge. Imagine an IMT has arrived and requested that one person be assigned to the IMT who could serve as a community liaison. The role of the community liaison would be to help inform the IMT about local conditions, contacts, priorities, culture, and politics.

1. Is there a person in your community or within the local U.S. Forest Service that you would trust to play this role? (Yes/No)

2. If yes, in the spaces below, please list the titles of up to three people and their associated organization/agency (if applicable) that you feel would be the best person to serve as a community liaison to an incident management team from outside the area. Actual Community Bridgers during an Incident. The post-fire survey elicited data on a range of variables, including multiple aspects of network interaction and performance during the incident. This study focused on two open-ended questions regarding bridging actors active during the incident. The two questions asked of all respondents were: 
1. Over the course of the incident, were there one or more local individuals within the USFS or other host and cooperator agencies that were particularly helpful to you in understanding how to work most effectively with an IMT? If yes, please list them below. [IMT Bridge]

2. Over the course of this incident, were there local individuals within the USFS or other host and cooperator agencies who took a leadership role in helping to maintain effective communication and coordination among the different agencies/organizations? If yes, please list them below [Network Leader]

Coding Types of Agencies

The resulting database consisted of 244 pre-fire nominations of trusted bridgers from 102 respondents in 19 counties. It also included 117 nominations of actual bridgers to the IMT and 79 nominations of network leaders on actual fire events during the 2013 fire season. Our first stage of analysis was to code each agency in our response networks according to organization type (e.g., county emergency management, municipal government, federal land agency, etc.). The full list of agency types and nominations collected from each type for our surveys can be found in Table 2. We then applied these codes to the organizational affiliations of individuals nominated as bridges in our pre-fire and post-fire surveys. Using a standard network analysis format, characteristics of nominators and nominates for both pre-fire as well as post-fire nominations were relationally linked in the database to examine patterns concerning who nominated whom.

INSERT TABLE 2 ABOUT HERE [Table 2. Respondents by Agency Type] Findings 
Which agencies were most trusted ahead of fire season to bridge between local responders and federal outsiders?

Figure 1 displays nomination rates per organization type for pre-fire nominations for IMT bridge liaisons, incident-based IMT bridge liaisons, and incident-based inter-agency bridges. When looking at these results, it is important to remember that pre-fire nominations were to identify individuals in their community or within the local U.S. Forest Service who they would trust to bridge between the local and federal (IMT) responders. For pre-fire bridge liaison nominations, individuals in professional fire service roles were nominated most frequently by far, with 40 percent of all nominations. The second-most frequently nominated agency types, federal land agencies, and municipal government receive 13 and 12 percent of total nominations, respectively, followed closely by law enforcement and county OEM. All others (e.g., state land agency, local landowners, human services, etc.) together received only 13 percent of nominations combined. Many respondents seemed to put trust into county leaders. Though locally-based federal land agencies were the second most frequently nominated agency types in the pre-fire survey, local agencies, when taken together (fire service, municipal and county government, OEM, human services, and landowners) account for 84 percent of all nominations of trusted bridgers ahead of the 2013 fire season.

INSERT FIGURE 1 [Figure 1: Agency Nominees for Pre-Fire IMT Liaisons, Incident-Based IMT Liaisons, and Incident-Based Interagency Bridges] ABOUT HERE

Which Agencies Actually Bridged between Local Responders and Federal Outsiders during the 2013 Fire Season?

Post-fire respondents were asked whether there were one or more local individuals within the US Forest Service or other host and cooperator agencies that were particularly helpful to 
them in understanding how to work most effectively with an IMT over the course of the fire. Overwhelmingly, the most frequently nominated (34\%) agency types for having served as bridges to the IMT during wildfire incidents were individuals in federal land agency roles. An equal percentage of nominations referred to non-bridging ties directly to IMT personnel. Individuals in other types of agencies each received less than 10 percent of nominations and a total of 32 percent of nominations combined.

Which Agencies Emerged in Promoting Coordination among the Responder Network during the 2013 Fire Season?

The types of agencies nominated as providing interagency bridges were similar to the types of agencies nominated as incident management team bridges. When respondents were asked whether there were local individuals within the US Forest Service or other host and cooperator agencies who took a leadership role in helping to maintain effective communication and coordination among the different agencies and organizations responding to the fire, we yielded a total of 79 nominations. While the order of nominations differs somewhat, the top six agency types for individuals nominated as bridges between agencies is the same as that for bridges to incident management teams. As with nominations for bridges to the incident management team, nominations for interagency bridges were most frequently for individuals in federal land agency roles with 33 percent, followed by individuals in IMT roles, who received 20 percent of the nominations. Nominations for individuals in fire services were third most common at 13 percent, followed by county emergency management (11\%), and state land agencies (10\%). Other agency types received less than ten percent of total nominations.

Who Trusts Whom to Serve as a Bridger? 
We were interested in examining whether there were patterns in the types of agencies nominated by different respondent agency types. To do so, we generated a network graph of agency nominators and nominees (see Figure 2). In total, 45 percent of respondents nominated bridges from the same agency type as their own in the pre-fire survey, indicating a relatively high tendency toward homophily in bridging actor preference and trust (shown as loops in Figure 2). Interestingly, of the 244 pre-fire nominations, 53 percent $(n=130)$ of them specified a person's name for the liaison they were nominating, thus indicating that they had some degree of personal familiarity_or relational embeddedness (Nowell and Steelman 2014)—with nominees. Fire services and municipal government most frequently nominated incident management team liaisons within their own respective agency types, though we can see that law enforcement, county emergency managers, and county government also nominated agencies within their own agency types, albeit to a lesser extent. The most central agency types in the network-fire service, law enforcement, and county government — are those that receive the overall greatest number of ties. However, looking at the diversity of nominating agency types (indicated by node size), we can see that county emergency management and federal land agencies are perceived and trusted as bridging actors by a notable range of agency types, although their overall frequency of nomination is less than the more central agencies.

\section{INSERT Figure 2: Network Graph of IMT Liaison Nominations Prior to Fire Season ABOUT HERE \\ Who was a Bridge for Whom during the Incident?}

Figure 3 is a network graph of agency type nominators and agency types nominated as having served as intermediaries between nominators and IMTs on their respective wildfire incidents. Overall, only three percent of respondents named bridging actors from their own 
agency type, indicating a much lower tendency toward homophily than in the pre-fire nominations $(45 \%)$. One noteworthy pattern in the incident-based IMT bridge nominations is the low level of bridging in the network overall (indicated by the centrality and diversity of direct ties to IMTs). Another notable pattern is the increased centrality and diversity of bridging ties through federal land agencies. Agency types previously central to the pre-fire nomination network — fire service, law enforcement, and county government—were decidedly marginal as bridging actors in the incident based networks. We can also see that state land agencies emerged as more central and frequent bridging agencies during wildfire incidents.

\section{INSERT Figure 3: Network Graph of IMT Bridges during Wildfire Incidents ABOUT HERE} Who was Viewed as a Network Leader by Whom during the Incident?

We next identified patterns of agency type nomination by respondents from each agency type in our sample (see Figure 4). Overall, seven percent of interagency bridges were from the same agency type as the respondents (slightly higher homophily than IMT bridges during the fire, but still much lower than the $45 \%$ of pre-fire nominations). Homophilic nominations primarily came from fire service and law enforcement, with one from within human services agencies. Here we can see that county emergency managers emerged as the most central agency type, though county emergency management offices themselves primarily identified federal land agencies as network leaders and federal land agencies are nominated by a greater range of agency types than county emergency management (indicated by node size). Interestingly, IMTs are both less central and receive less diversity of nominations as network leaders than they did as direct ties to agencies in the network in the IMT liaison nominations. Finally, state land agencies retain a noticeable degree of centrality and diversity of nominations in both incident-based networks. 


\section{INSERT Figure 4: Network Graph of Interagency Bridges during Wildfire Incidents ABOUT HERE}

\section{Discussion}

At the outset of this article, we suggested that there were two plausible, but contradictory, bodies of theory that suggested who people might seek out as bridgers and who they would actually go to during a disaster. Our evidence generally supports both expectations, as well as demonstrates an interesting dynamic between the two tendencies. Overall, pre-fire nominations for IMT liaisons were consistent with our similarity thesis that in a pre-fire scenario respondents would be more likely to name those who were more similar to themselves. The three most commonly nominated agency types - fire services, federal land agencies, and law enforcementare arguably intuitive selections as leaders in wildfire emergency response. Roughly half of all pre-fire nominations were consistent with the similarity thesis, or homophily (Petev 2013; McPherson et al. 2001) and relational embeddedness (familiarity) (Nowell and Steelman 2014), both of which are consistently associated with trust and the formation of social groups (Burt 1992). However, while similarity and familiarity appear to be reliable indicators of how people expect to organize in an emergency, this does not hold up for actual incident network performance in the cases we studied.

The most noteworthy finding in this study is the difference in pre- and post-fire nominations for IMT bridges. Notably, fire services are overwhelmingly favored in pre-fire nominations, followed by federal land agencies, municipal government, and law enforcement as distant seconds to fire service. In the incident-based survey, however, we find that locally-based federal land agencies are by far the most commonly nominated bridging actors (34\%). This is an important distinction, as it reveals that the agencies most commonly trusted and expected to play 
a bridging role (fire services) do not actually play this role in practice and it is instead one of the least trusted agencies (local federal land) that does play this role.

Interestingly, rate of direct (i.e., non-bridging) ties to IMTs (34\%) is equal to that of locally-based federal land agencies. This indicates that IMTs engage in a fair amount of direct coordination with a range of agency types in the network. Given the structure of IMTs, with assigned roles for liaising with local agencies and disseminating public information, as well as regular meetings with cooperating agencies as part of operations, this coordinating role is not entirely surprising. Currently, there are no established standards for appropriate levels of bridging, nor is a "one size fits all” prescription likely possible or even necessarily desirable. However, this finding presents an interesting metric for comparison in future studies of bridging versus direct ties to IMT in wildfire response networks.

When we examine nomination patterns exhibited by different types of nominating agencies, we note the tendency of respondents to nominate agencies of the same type as their own. Homophilic preferences could of course prove problematic for the same reasons discussed in the opening pages of this manuscript — complex networks, especially in emergency response, where time is critical, can be overburdened with demands from multiple subgroups who do not exhibit similar preferences. Trust beyond one's immediate cohort could potentially facilitate more effective bridging in complex incident networks. However, we see a precipitous drop in homophilic nominations in actual incident networks, which suggests that local responders in many ways reframed their homophilic preferences during the incidents. This also indicates that an important way that IMTs manage incident coordination and local relational dynamics is through liaising directly with many organizations in the network. This also ultimately suggests 
that the dissimilarity thesis (Steelman et al. 2012; Heberlein 2012; Schultz 2011) might hold some weight over the similarity thesis in actual practice.

It is, however, somewhat surprising that county offices of emergency management do not rank higher in pre-fire and post-fire IMT liaison nominations. We would expect them to rank higher because their institutional roles are primarily to facilitate coordination between agencies and they have less direct operational responsibilities (e.g., firefighting). This is especially so in incident-based nominations, where county emergency management ranks even lower than they do in pre-fire nominations as IMT bridges, suggesting that they, like fire service leaders, play a less central role in response network bridging than is expected by the local community. One possible explanation for the less central role performed by county emergency managers may be related to the order in which agencies are mobilized in response. Since wildfires frequently emerge from the forest, the Forest Service naturally engages first, frequently followed by law enforcement and fire service, who must respond to road closure and structural protection imperatives in the earliest stages of wildfire spread to WUI. Similarly, the issue might be jurisdictional, as landownership (e.g., federal, state, private, county, etc.) may often dictate who is mobilized in leadership capacities. This may take precedence over the land's broader association with an adjoining county, especially in early stages of an event. These other agencies are therefore more likely to be centrally placed in the network before county emergency managers are engaged in response. Interestingly, while county emergency managers are not particularly central as agencies bridging to IMTs, they do appear as the most central agency type nominated as a network leader during wildfire incidents, though federal land agencies receive nominations from a greater range of agency types. This indicates that their roles are not entirely diminished in responder network coordination. 
One way to interpret the discrepancy in pre-fire and post-fire nominations is to note that, when considering hypothetical wildfire emergency scenarios, respondents might be expected to first think of fire service agencies as natural leaders in these contexts. It is also worth noting that the rural regions of the American Northwest in our sample are known to exhibit a degree of mistrust in the federal government and tensions with federal land agencies are common (Anderson 2006: Fleming et al. 2015: Carroll et al. 2004; Carroll et al. 2006), which could explain why these agencies are less likely to be nominated in hypothetical scenarios. However, it is important to consider whether this finding indicates that there are potential missed opportunities in network organization in wildfire response in the region. Specifically, we are left to consider why fire service and other local agencies that a majority of respondents expect to play bridging roles in wildfire response are often less central, while federal land agencies instead take the lead in these roles.

\section{Conclusion}

This study identifies important patterns of preference and practice for bridging organizations in complex interagency networks in wildfire response in the American Northwest. In large scale disasters, like wildfire, local and extra-local actors must come together to effectively respond to the threat. This creates conditions where bridging actors play an essential role in the effectiveness of disaster response. Our research brings much needed empirical evidence to bear on the role of bridging actors in these disaster response networks. Building knowledge about bridging roles in disaster networks remains critical because coordination of action and the flow of information is essential to successful incident response and the prevention of conflict and cascading effects throughout the network. 
Our findings can be divided into two primary areas - theoretical and practical.

Theoretically, our study examines relationships between theses of similarity and dissimilarity in novel contexts of pre-incident and post-incident response networks. We find that idealized cognitive models do not correspond to practice; while there is a clear trend in preference for similarity in pre-incident networks, this does not tell us much about how incident-based networks actually form. Contrary to the expectation that similarity would predict the formation of networks, we find that it forms a key element of how people envision network formation, while there is instead a low correspondence between expectations and practice.

By understanding who people anticipated seeking and then identifying who actually played these roles, we can plan more realistically for effective disaster response. Practically, our findings suggest that: (a) there are agency types that are preferred as bridges, yet not mobilized as such (fire service and, to a lesser extent, county emergency managers); and (b) a possibility that agencies well-suited to play bridging roles (county emergency management) are less likely to play these roles in practice. Awareness of these patterns can be useful to agencies involved in wildfire response in a number of ways. First, it is an opportunity-outside of immediate emergency contexts - for agencies involved in wildfire response to examine and consider the preferences and practices of other organizations in incident-response networks. Second, we feel this points to the need for wildfire-prone communities to build greater networks of trust and interaction outside of fire season to extend trust in agencies other than their own. For example, tabletop exercises and response drills go a long way in building local relationships as people tend to trust familiar individuals over those they have not previously encountered. This is important in wildfire contexts as involved individuals are more likely to reach out to persons with whom they have an existing relationship. Ultimately, these exercises that build larger and more diverse 
networks can help to fill those gaps in the network during times of crisis, creating increased potential for individuals in local agencies to serve as bridging actors with federal agencies involved on the same incident. Such activities could prove instrumental in building greater consensus in perceiving which actors and agencies could be most effective in playing network leadership roles during an emergency. Finally, it is an opportunity to interrogate competing operational and leadership priorities of the different agencies in a given network. In an emergency, operational priorities cannot suffer as a result of network leadership demands, but network leadership capacities can be augmented so as to minimize such risks. Ultimately, incident response is a social environment laden with culturally influenced perceptions and practices.

Our findings point to a need to bridge several social, cultural and, ultimately, operational gaps in wildfire response networks at the urban interface. Further research could help to refine our understanding of these gaps and improve on some of the limitations of this study. One limitation is that we do not have a high degree of correspondence in our pre- and post-fire sample, meaning it is difficult to examine change in specific respondents' nominations from prefire to post-fire samples; however, attrition and varying response rates are common issues faced by all large survey studies, so this will be difficult to significantly improve upon in studies of similar scope. Additionally, our samples over-represented fire service and municipal government in the pre-fire sample and county government, fire service, law enforcement, county emergency management, and state government in the post-fire sample. While this undoubtedly influenced the distribution and centrality of certain types of nominees, we are confident in the general patterns reported here, as we did not attempt to identify bridging nomination patterns by agency type. Nonetheless, future studies might develop recruitment strategies that better represent the 
diversity of agencies in wildfire response networks. Another course of further study could be to focus on a smaller set of incidents, although there would likely be pronounced challenges in anticipating sites of WUI wildfires using smaller regional sampling frames for pre-fire surveys. Finally, further studies could attempt to follow up with respondents on specific wildfire incidents to probe for local interpretations for difference or correspondence in bridging actor preference and practice.

Ultimately, given the potential relational risks inherent in large wildfire response networks, research into the relational factors that influence performance and inclusion stands to make noteworthy contributions to theory and practice. While there is a variety of relational and other contextual factors that are unique to large wildfire response, building a greater corpus of empirical and theoretical knowledge in wildfire response networks has the potential to contribute to theory and practice in a variety of risk, hazard, and disaster contexts. Disaster risk reduction, hazard mitigation, emergency response, and disaster recovery all entail the mobilization of multiple organizations, communities, and individuals and increased knowledge of the factors influencing effective network mobilization and the meaningful inclusion of all stakeholders is fundamental to success in these areas.

\section{References}

Aldrich, D. P. (2012) Building Resilience: Social capital in post-disaster recovery. University of Chicago Press, Chicago.

Anderson, B. (1983) Imagined Communities: Reflections on the origin and spread of nationalism. Verso, New York.

Anderson, M. K. (2006) Tending the Wild: Native American knowledge and the management of California's natural resources. University of California Press, Berkeley.

Baruch, Y., and B. C. Holtom (2008) 'Survey Response Rate Levels and Trends in Organizational Research’. Human Relations 61(8), pp.1139-1160.

Bodin, Ö., B. Crona, and H. Ernstson (2006) 'Social Networks in Natural Resource Management: What is there to learn from a structural perspective?' Ecology and Society 11(2):r2. www.ecologyandsociety.org/vol11/iss2/resp2/ 
Brass, D. J., J. Galaskiewicz, H. R. Greve, and W. Tsai (2004) 'Taking Stock of Networks and Organizations: A multilevel perspective'. The Academy of Management Journal 47(6), pp.795817.

Brown, T. J., B. L. Hall, and A. L. Westerling (2004) 'The Impact of Twenty-First Century Climate Change on Wildland Fire Danger in the Western United States: An application perspective'. Climate Change 62, pp. 365-388.

Bryson, J. M., B. C. Crosby, and M. Middleton Stone (2006) 'The Design and Implementation of Cross-Sector Collaborations: Propositions from the literature'. Public Administration Review 66, pp. 44-55.

Burnett, M., and C. Davis (2002) 'Getting out the Cut: Politics and National Forest Timber Harvests, 1960-1995'. Administration and Society 34, pp. 202-228.

Burt, R. S. (2001) 'Structural Holes versus Network Closure as Social Capital'. In N. Lin, K. S. Cook, and R. S. Burt (eds) Social Capital: Theory and research. Aldine de Gruyter, New York, pp. 31-56.

Burt, R. S. (1992) Structural Holes. Harvard University Press, Cambridge.

Carlile, P. R. (2002) 'Transferring, Translating and Transforming: An integrative framework for managing knowledge across boundaries'. Organization Science 15(5), pp. 555-568.

Carroll, M. S., P. J. Cohn, D. N. Seesholtz, and L. L. Higgins (2004) 'Fire as a Galvanizing and Fragmenting Influence on CommunitiesL The Case of the Rodeo-Chediski Fire'. Society and Natural Resources 18, pp. 301-320.

Carroll, M. S., L. L. Higgins, P. J. Cohn, and J. Burchfield (2006) 'Community Wildfire Events as a Source of Social Conflict'. Rural Sociology 71(2), pp. 261-280.

Coser, R. (1975) 'The Complexity of Roles as Seedbed of Individual Autonomy'. In Lewis Coser (ed) The Idea of Social Structure: Essays in honor of Robert Merton. Harcourt Brace Jovanovich, New York, pp. 237-263.

Cuthane, P. J. (1981) Public Land Politics: Interest group influence on the Forest Service and The Bureau of Land Management. Johns Hopkins University Press, Baltimore.

Fedkiw, J. (1998) Managing Multiple Uses on National Forests, 1905-1995: A 90 year learning experience and it isn't finished yet. United States Department of Agriculture Forest Service.

Fitzpatrick, C., and D. S. Mileti (1991) 'Motivating Public Evacuation'. International Journal of Mass Emergencies and Disasters 9(2), pp. 137-152.

Fleming, C. J., E. B. McCartha, and T. A. Steelman (2015) 'Conflict and Collaboration in Wildfire Management: The Role of Mission Alignment'. Public Administration Review 75(3), pp. 445-454.

Frank, K. A. (2009) 'Quasi-ties: Directing resources to members of a collective'. American Behavioral Scientist 52, pp. 1613-1645.

Granovetter, M. (1982) 'The Strength of Weak Ties: A network theory revisited'. In P. Marsden and N. Lin (eds) Social Structure and Network Analysis. Sage Publications, Beverly Hills, pp. 105-130.

Heberlein, T. A. (2012) Navigating Environmental Attitudes. Oxford University Press, Oxford. 
John, D., and G. Christopher (2000) 'A Partnership for Regional Collaboration'. Review of Policy Research 17(2/3):47-61.

Kapucu, N. (2006) 'Interagency Communication Networks during Emergencies: Boundary Spanners in Multiagency Coordination'. American Review of Public Administration 36(2), pp. 207-225.

Krannich, R. S., and M. D. Smith (1998) 'Local Perceptions of Public Lands Natural Resource Management in the Rural West: Toward improved understanding of the "revolt in the west". Society and Natural Resources 11(7), pp. 677-695.

Lave, J. (1988) Cognition in Practice: Mind, mathematics, and culture in everyday life. Cambridge University Press, New York.

Levi, M., and L. Stoker (2000) 'Political Trust and Trustworthiness'. Annual Review of Political Science 3, pp. 475-507.

Lightfoot, K. G., R. Q. Cuthrell, C. J. Striplen, and M. G. Hylkema (2013) 'Rethinking the Study of Landscape Management Practices Among Hunter-Gatherers in North America'. American Antiquity 78(2), pp. 285-301.

Lundin, M. (2007) 'Explaining Cooperation: How resource interdependence, goal congruence, and trust affect joint actions in policy implementation'. Journal of Public Administration Research and Theory 17(4), pp. 651-673.

Manring, S. L. (2007) 'Creating and Managing Interorganizational Learning Networks to Achieve Sustainable Ecosystem Management’. Organization and Environment 20(3), pp. 325326.

McCaffrey, S., E. Toman, M. Stidham, and B. Shindler (2013) 'Social Science Research Related to Wildfire Management: An overview of recent findings and future research needs'. International Journal of Wildland Fire 22(1), pp. 15-24.

McCarthy, J. (2002) 'First World Political Ecology: Lessons from the Wise Use movement'. Environment and Planning 34, pp. 1281-1302.

McEntire, D. A. (2007) Disciplines, Disasters and Emergency Management: The convergence and divergence of concepts, issues and trends from the research literature. Charles Thomas, Springfield, IL.

McPherson, M., L. Smith-Lovin, and J. M. Cook (2001) 'Birds of a Feather: Homophily in social networks'. Annual Review of Sociology 27, pp. 415-444.

Milward, H. B., and K. G. Provan (2000) 'Governing the Hollow State'. Journal of Public Administration Research and Theory 10(2), pp. 359-380.

Nowell, B., and T. A. Steelman (2014) 'Communication under Fire: The role of embeddedness in the emergence and efficacy of disaster response communication networks'. Journal of Public Administration Research and Theory 24(4),

Perrone, V., A. Zaheer, and B. McEvily (2003) 'Free to be Trusted? Organizational constraints on trust in boundary spanners'. Organization Science 14(4), pp. 422-439.

Petev, I. D. (2013) 'The Association of Social Class and Lifestyle: Persistence in American Sociability, 1974-2010'. American Sociological Review 78(4), pp. 633-661. 
Powell, W. W., K. W. Koput, D. R. White, and J. Owen-Smith (2005) 'Network Dynamics and Field Evolution: The growth of interorganizational collaboration in the life sciences'. American Journal of Sociology 110(4), pp. 1132-1205.

Provan, K. G., and H. B. Milward (2001) 'Do Networks Really Work? A framework for evaluating public sector organizational networks'. Public Administration Review 61(4), pp. 414423.

Pyne, S. J. (2001) Year of the Fires: The story of the Great Fires of 1910. Viking Press, New York.

Rogers, E. M. (2003) Diffusion of Innovations, $5^{\text {th }} \mathrm{ed}$. Free Press, New York.

Running, S. W. (2006) 'Is Global Warming Causing More, Larger Wildfires?' Science 313, pp. 927-928.

Schneider, M., J. Scholx, M. Lubell, D. Mindruta, and M. Edwardsen (2003) 'Building Consensual Institutions: Networks and the national estuary program'. American Journal of Political Science 47(1), pp. 143-158.

Schoennagel, T., C. R. Nelson, D. M. Theobald, G. C. Carnwath, and T. B. Chapman (2009) 'Implementation of National Fire Plan Treatments Near the Wildland-Urban Interface in the Western United States'. Proceedings of the National Academy of Sciences 106(26), pp. 1070610711.

Schultz, P. W. (2011) 'Conservation Means Behavior'. Conservation Biology 25(6), pp. 10801083.

Steelman, T. A., and S. McCaffrey (2012) 'Best Practices in Risk and Crisis Communication: Implications for natural hazards management'. Natural Hazards 65(1), pp. 683-705.

Steelman, T. A., B. Nowell, D. Bayoumi, and S. McCaffrey (2012) 'Understanding Information Exchange during Disaster Response: Methodological Insights from Infocentric Analysis’. Administration \& Society 46(6), pp. 707-743.

Theobald, D. M., and W. H. Romme (2007) 'Expansion of the US Wildland-Urban Interface'. Landscape and Urban Planning 83(4), pp. 340-354.

Velez, A., J. Diaz, and T. U. Wall. (Under review) 'Potential for multimedia dissemination of the Sana Ana Wildfire Threat Index: Understanding information seeking and wildfire preparedness in Southern California WUI residents'.

Walker, P. A. (2003) 'Reconsidering "Regional” Political Ecologies: Toward a political ecology of the rural American West'. Progress in Human Geography 27(1), pp. 7-24.

Winter, G., C. A. Vogt, and S. McCaffrey (2004) 'Examining Social Trust in Fuels Management Strategies'. Journal of Forestry 102, pp. 8-15. 
Table 1. Similarity and Dissimilarity Theses Similarity Thesis

Dissimilarity Thesis

People will likely see those with whom they are

There will be a low correspondence between prefamiliar, who are similar to themselves (homophily), and whom they trust as ideal bridgers during a disaster

These preferences are important and can help outsiders better connect to locals, but high levels of preference for similarity can impede network bridging incident preferences and actual composition of networks during wildfire incidents

This is the result of novel and emergent network configurations in emergencies and operational priorities that override bridging priorities for some agencies.

These factors may curtail the problems associated with high levels of preferences for similarity, but excessive dissimilarity could also negatively affect network performance.

Table 2. Total Nominations from each Agency Type

\begin{tabular}{|c|c|c|c|}
\hline Nominating Agency Type & $\begin{array}{l}\text { Pre-Fire IMT } \\
\text { Liaison } \\
\text { Nominations }\end{array}$ & $\begin{array}{l}\text { Incident-Based IMT } \\
\text { Liaison Nominations }\end{array}$ & $\begin{array}{c}\text { Incident-Based } \\
\text { Network Leader } \\
\text { Nominations }\end{array}$ \\
\hline Animal Services & 8 & 0 & 0 \\
\hline $\begin{array}{l}\text { County Office of Emergency } \\
\text { Management (OEM) }\end{array}$ & 29 & 13 & 9 \\
\hline County Government & 17 & 13 & 6 \\
\hline Fire Service & 102 & 40 & 33 \\
\hline Law Enforcement & 19 & 19 & 17 \\
\hline Municipal Government & 69 & 3 & 1 \\
\hline $\begin{array}{l}\text { Human Services (EMT, American } \\
\text { Red Cross, Hospital, etc.) }\end{array}$ & $*$ & 10 & 13 \\
\hline Federal Land Agency & $*$ & $* *$ & $* *$ \\
\hline Landowner & $*$ & 7 & 0 \\
\hline State Government & $*$ & $* *$ & $* *$ \\
\hline State Land Agency & $*$ & 8 & 0 \\
\hline Miscellaneous Non-Government & $*$ & 4 & 0 \\
\hline Utilities & $*$ & 0 & 0 \\
\hline Total & 244 & 117 & 79 \\
\hline
\end{tabular}

* Not surveyed - Included only for reference to agency type; ** Survey responses excluded from present analysis for comparability with pre-fire sample. 


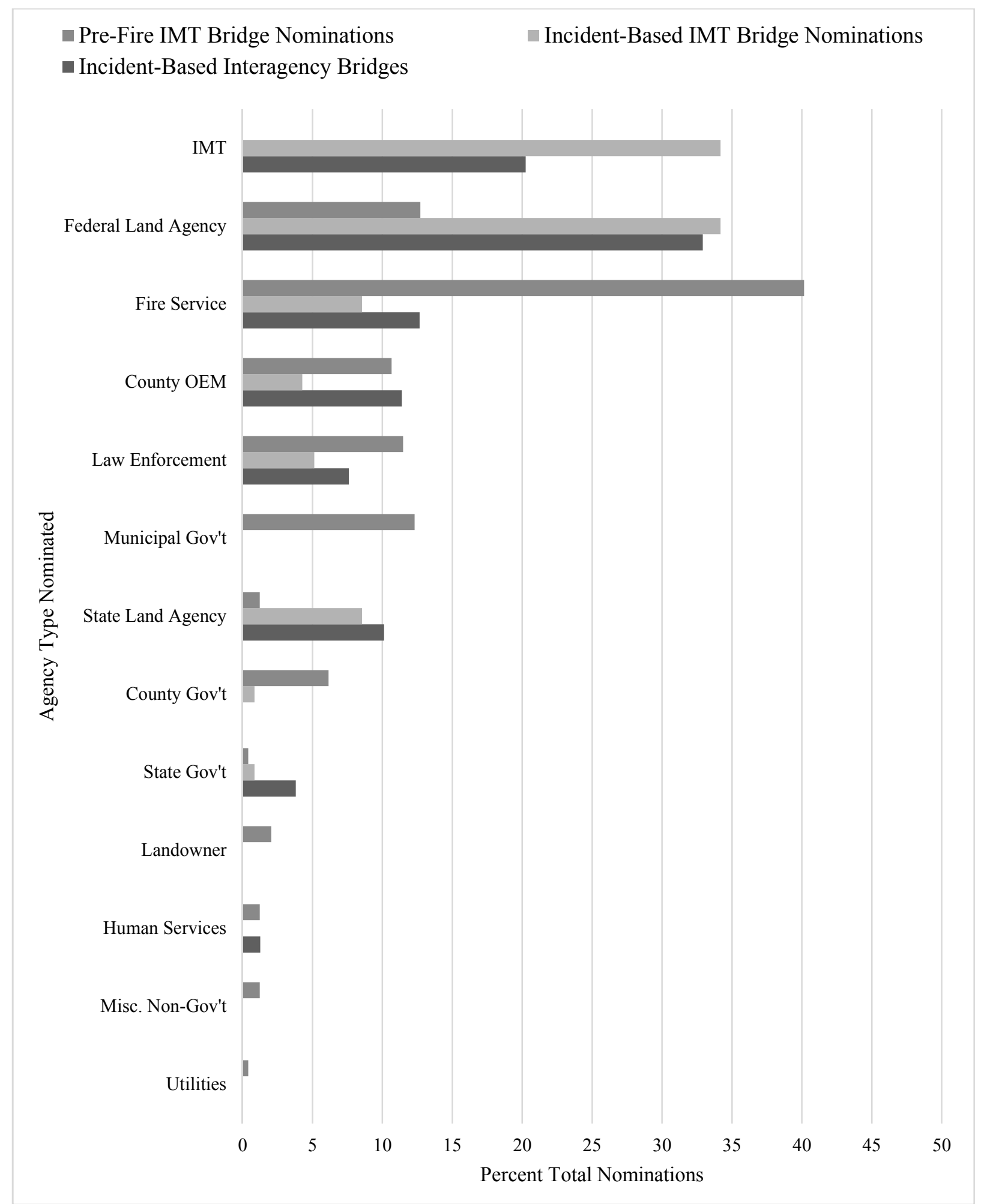

Figure 1: Agency Nominees for Pre-Fire IMT Liaisons, Incident-Based IMT Liaisons, and Incident-Based Interagency Bridges 


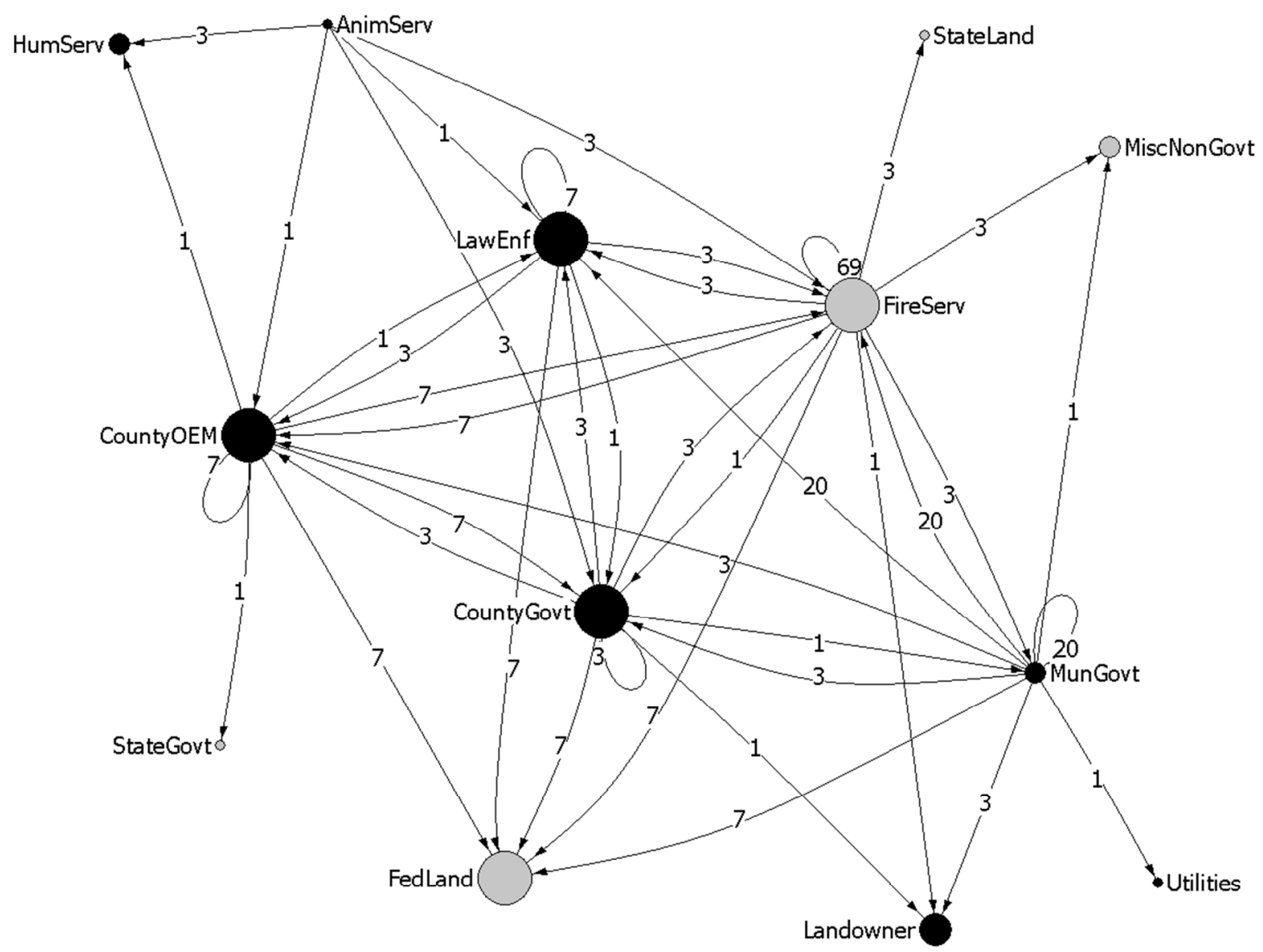

Figure 2: Network Graph of IMT Liaison Nominations Prior to Fire Season

Arrows indicate direction of nomination; Size indicates the number of agency types nominating (0-1, 2, 3, 5); Line numbers indicate the number of nominations from sending agency type to receiving agency type (dyadic); Centrality is overall number of ties; Black agency types are local and grey agency types are supralocal or mixed localsupralocal 
Figure 3: Network Graph of IMT Bridges During Wildfire Incidents

Arrows indicate direction of nomination; Size indicates the number of agency types nominating (0-1, 2, 3, 5); Line numbers indicate the number of nominations from sending agency type to receiving agency type (dyadic);

Centrality is overall number of ties; Black agency types are local and grey agency types are supralocal or mixed local-supralocal 


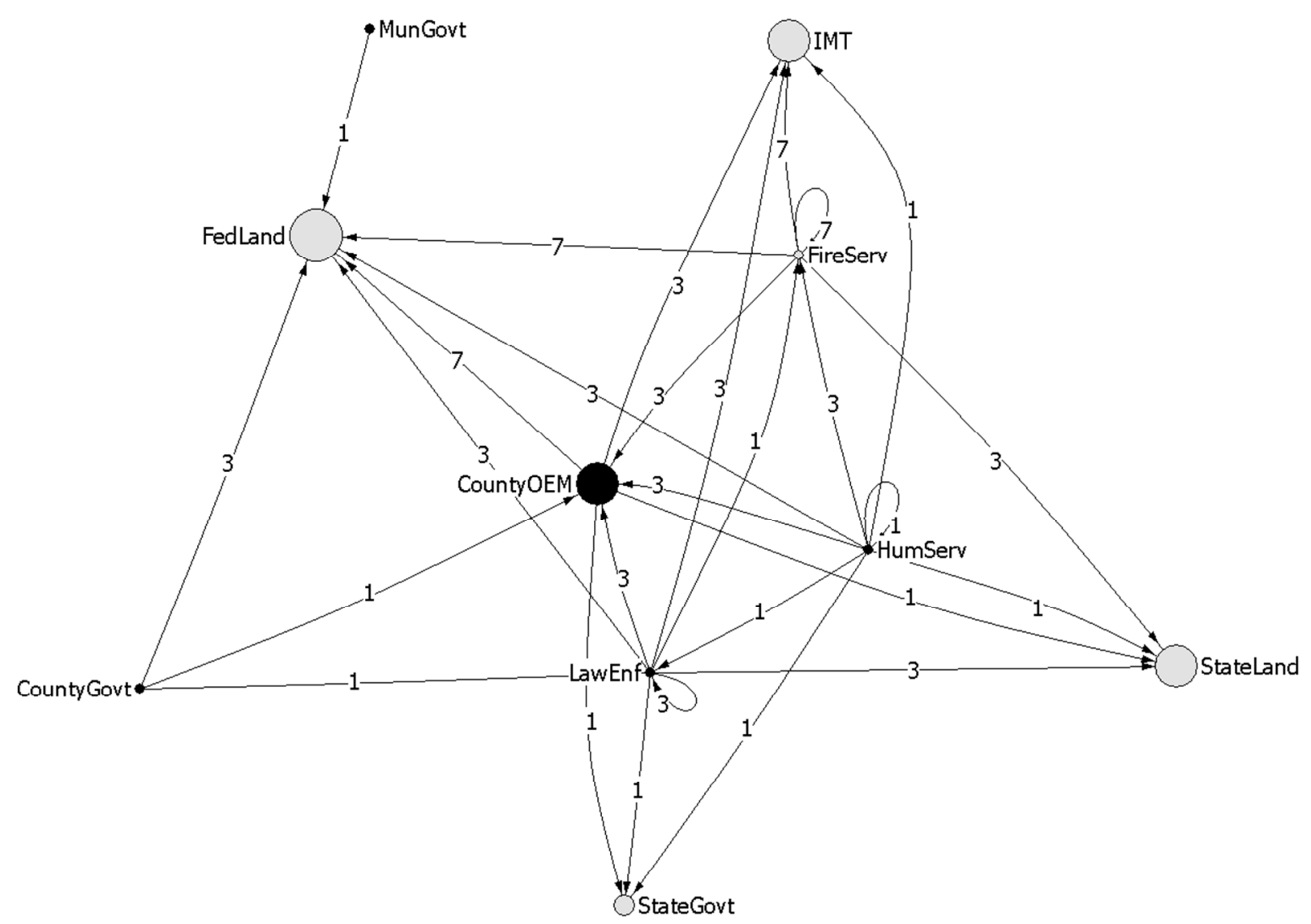

Figure 4: Network Graph of Interagency Bridges During Wildfire Incidents

Arrows indicate direction of nomination; Size indicates the number of agency types nominating (0-1, 2, 3, 5); Line numbers indicate the number of nominations from sending agency type to receiving agency type (dyadic); Centrality is overall number of ties; Black agency types are local and grey agency types are supralocal or mixed localsupralocal 


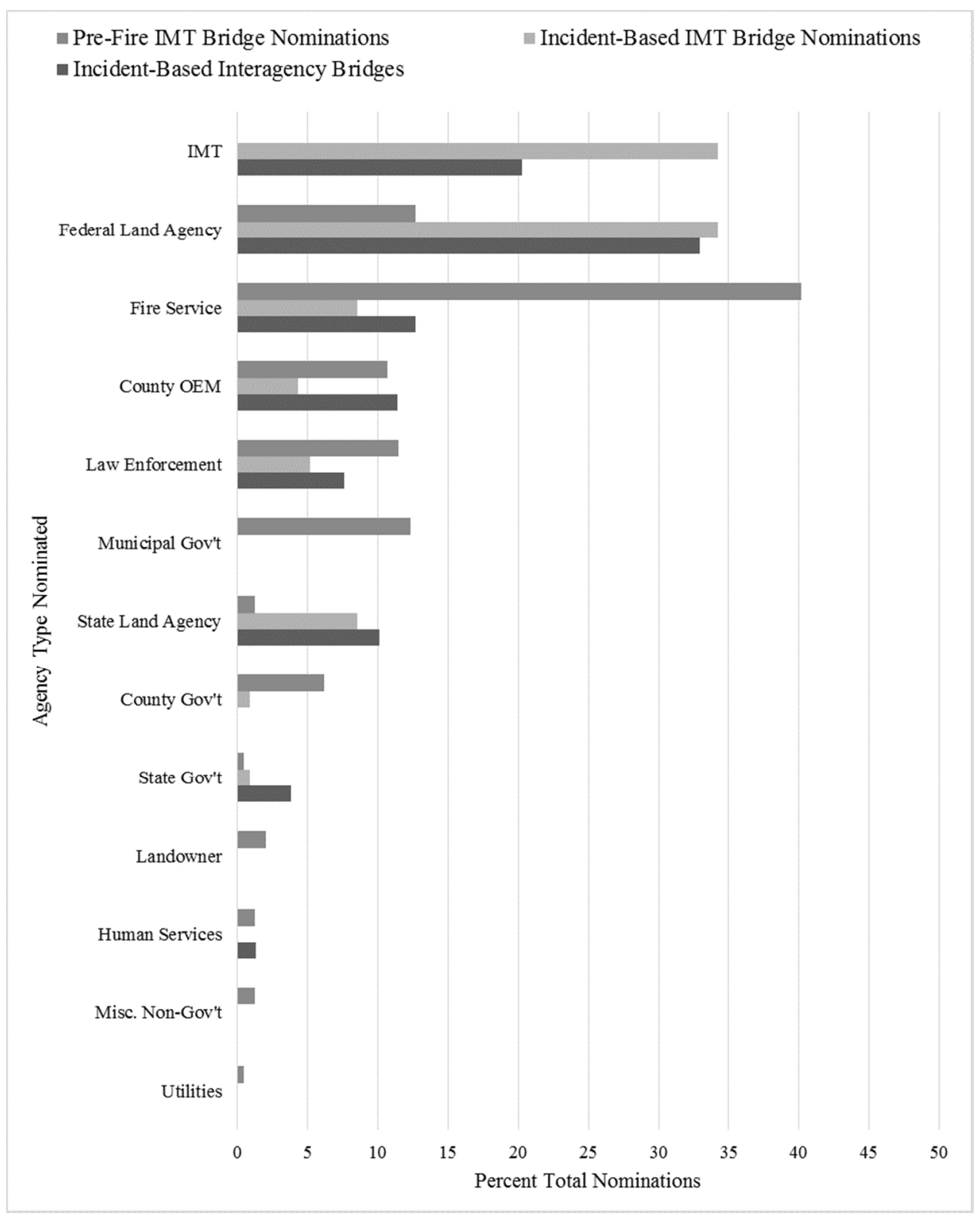

Figure 1: Agency Nominees for Pre-Fire IMT Liaisons, Incident-Based IMT Liaisons, and Incident-Based Interagency Bridges $163 \times 202 \mathrm{~mm}(150 \times 150$ DPI $)$ 


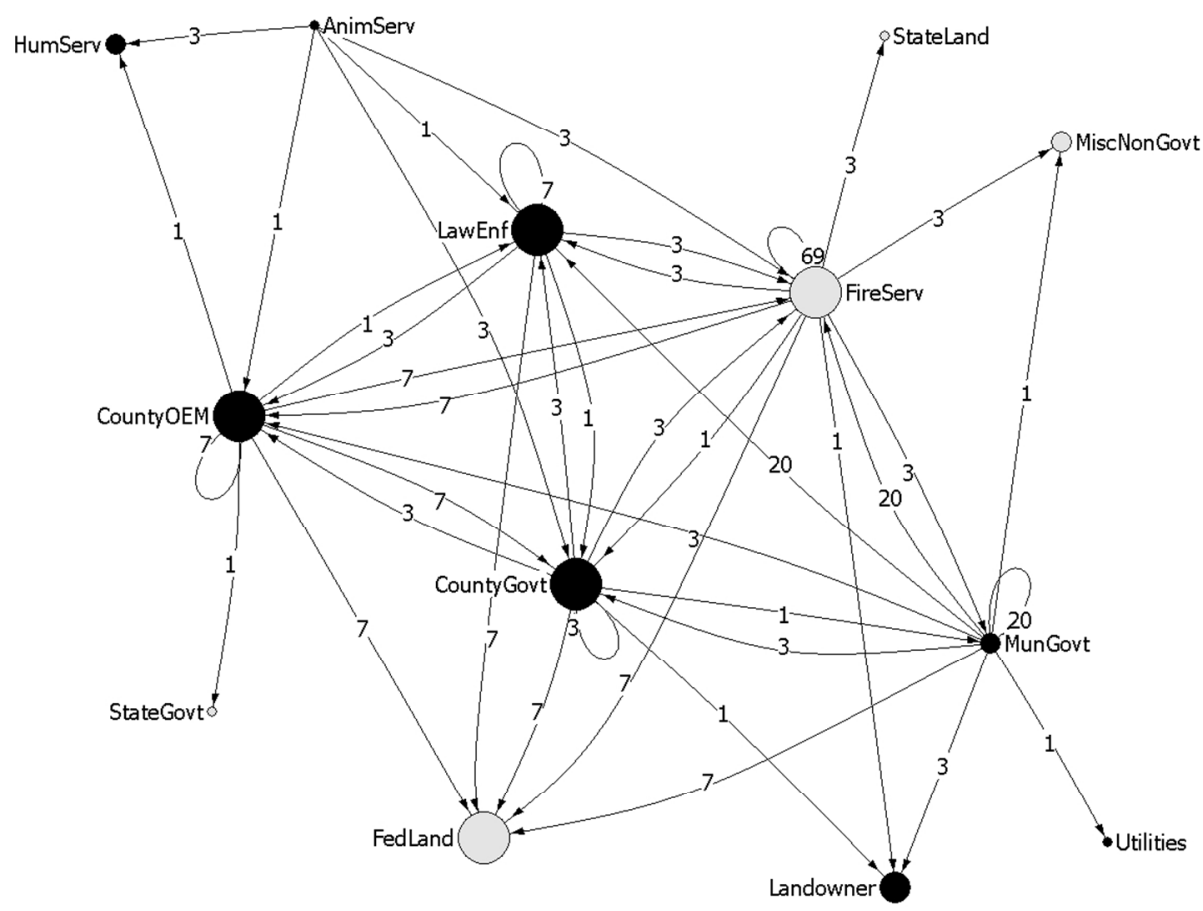

Figure 2: Network Graph of IMT Liaison Nominations Prior to Fire Season

Arrows indicate direction of nomination; Size indicates the number of agency types nominating $(0-1,2,3$, 5); Line numbers indicate the number of nominations from sending agency type to receiving agency type (dyadic); Centrality is overall number of ties; Black agency types are local and grey agency types are supralocal or mixed local-supralocal 


\section{Page 35 of 36}

\section{Disasters Journal}

1

2

3

4

5

6

7

8

9

10

11

12

13

14

15

16

17

18

19

20

21

22

23

24

25

26

27

28

29

30

31

32

33

34

35

36

37

38

39

40

41

42

43

44

45

46

47

48

49

50

51

52

53

54

55

56

57

58

59

60

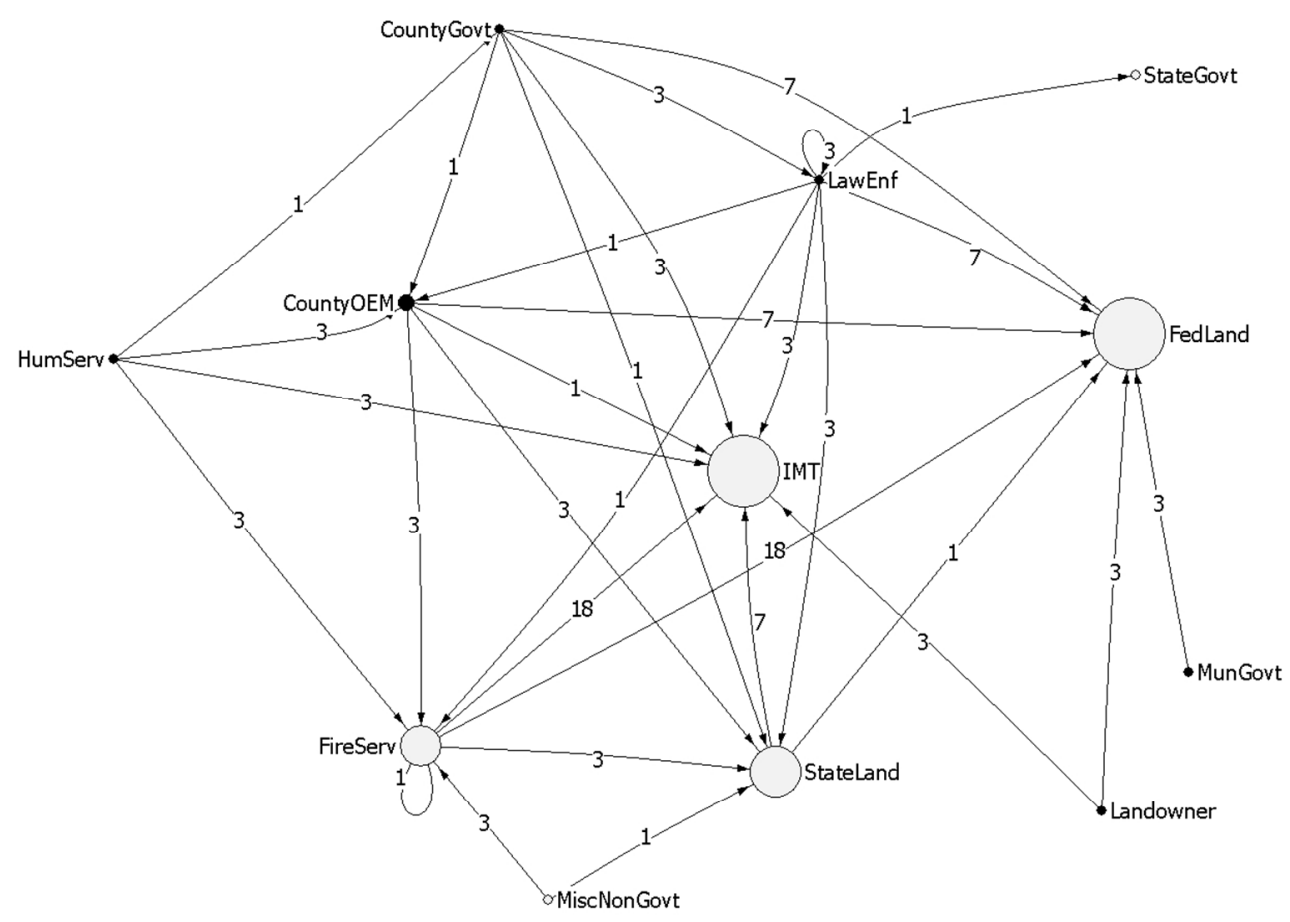

Figure 3: Network Graph of IMT Bridges During Wildfire Incidents

Arrows indicate direction of nomination; Size indicates the number of agency types nominating $(0-1,2,3$, 5 ); Line numbers indicate the number of nominations from sending agency type to receiving agency type (dyadic); Centrality is overall number of ties; Black agency types are local and grey agency types are supralocal or mixed local-supralocal 


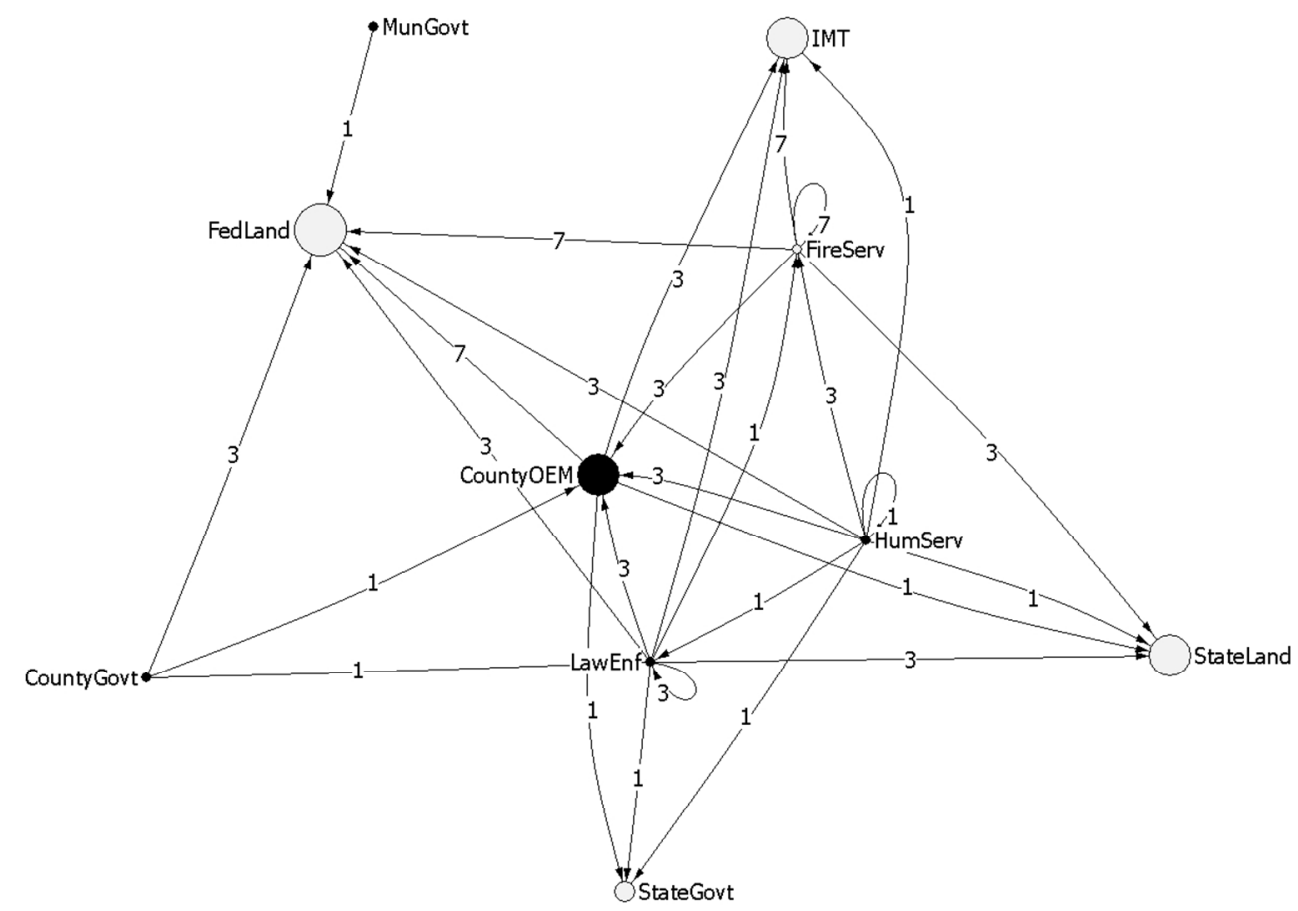

Figure 4: Network Graph of Interagency Bridges During Wildfire Incidents Arrows indicate direction of nomination; Size indicates the number of agency types nominating $(0-1,2,3$, 5); Line numbers indicate the number of nominations from sending agency type to receiving agency type (dyadic); Centrality is overall number of ties; Black agency types are local and grey agency types are supralocal or mixed local-supralocal 